\title{
Thistles of Greece and their potential value as Medicinal Crops: Study on their First Growth
}

\author{
Ilias TRAVLOS*, Ioannis E. ROUSSIS, Nikos KARAMPASIS, Ioanna TABAXI, Dimitrios PAPADIMITRIOU, \\ Nikolaos KATSENIOS and Dimitrios BILALIS
}

Laboratory of Agronomy, Agricultural University of Athens, Greece.

*)Corresponding author, e-mail: htravlos@yahoo.gr

BulletinUASVM Horticulture 73(1) / 2016

Print ISSN 1843-5254, Electronic ISSN 1843-5394

DOI:10.15835/buasvmcn-hort:11773

\begin{abstract}
Canadian thistle (Cirsium arvense (L.) Scop.), Milk thistle (Silybum marianum (L.) Gaertn.) and Scotch thistle (Onopordum acanthium L.) are weed species, which can be also useful medicinal plants. A preliminary seed germination test was conducted, while a greenhouse experiment was also established during 2015 at the Agricultural University of Athens, where seed germination, seedling emergence, first growth rate and biomass production of three biotypes of $S$. marianum, two biotypes of $C$. arvense and three biotypes of $O$. acanthium were evaluated. According to the results of this study, seed germination and seedling emergence were high for all species and biotypes. First growth rate and earliness were significant different between the several species. High biomass production was found in the biotypes originated from arable fields. In conclusion, this research work proved that there is a potential of exploitation of thistles according to their many uses. Seed germination, seedling emergence, first growth, biomass production and earliness of some biotypes seem rather satisfactory, while the high genetic variability of these three weeds can be used as a source for any future breeding attempts.
\end{abstract}

Keywords: Thistles, Cirsium arvense, Silybum marianum, Onopordum acanthium, seedling emergence.

\section{INTRODUCTION}

Canadian thistle (Cirsium arvense (L.) Scop.) is a weed species that even in low densities can cause major yield loss to several spring crops (Miller et al., 1994). Even being a weed, C. arvense is also a valuable medicinal plant (Khan et al., 2011). Milk thistle (Silybum marianum (L.) Gaertn.) can also be a serious weed; however, in many cases, it can be used because of its noticeable medicinal properties (Karkanis et al., 2011). Scotch thistle (Onopordum acanthium L.) can be useful because of its several properties. O.acanthium as medicinal plant has been traditionally used for its antibacterial, hemostatic, and hypotensive properties (Lajter et al., 2013).

The objective of this study was to evaluate seed germination, seedling emergence, first growth rate and biomass production of three biotypes of Silybum marianum, two biotypes of Cirsium arvense and three biotypes of Onopordum acanthium grown under the same conditions.

\section{MATERIALS AND METHODS}

Mature seed samples of several biotypes of thistles were collected from arable fields and fallow of central Greece during the summer of 2014. A preliminary seed germination test was conducted, while a greenhouse experiment was also established. Seeds were sown and plants were grown in $1 \mathrm{~L}$ pots $(12 \mathrm{~cm}$ diameter) containing perlite and soil (1:2 by volume) and watered as required. Soil was a clay loam (CL), the physicochemical characteristics of which (0- to $15-\mathrm{cm}$ depth increment) were clay $352 \mathrm{~g} / \mathrm{kg}$, silt $457 \mathrm{~g} / \mathrm{kg}$, sand $191 \mathrm{~g} / \mathrm{kg}, \mathrm{pH}\left(1: 2 \mathrm{H}_{2} 0\right) 8.2,1.75$ $\mathrm{g} / \mathrm{kg}$ total nitrogen, a medium supply of available phosphorus (P-Olsen $0.034 \mathrm{~g} / \mathrm{kg}$ ) and a good supply of available potassium $(0.88 \mathrm{~g} / \mathrm{kg})$. EC was $2700 \mu$ mhos, $\mathrm{CaCO}_{3} 330 \mathrm{~g} / \mathrm{kg}$ and organic matter content $24.4 \mathrm{~g} / \mathrm{kg}$. When seedlings were at 3-5 leaves stage, they were transplanted as to stay one plant per pot and first growth and biomass production were assessed. 

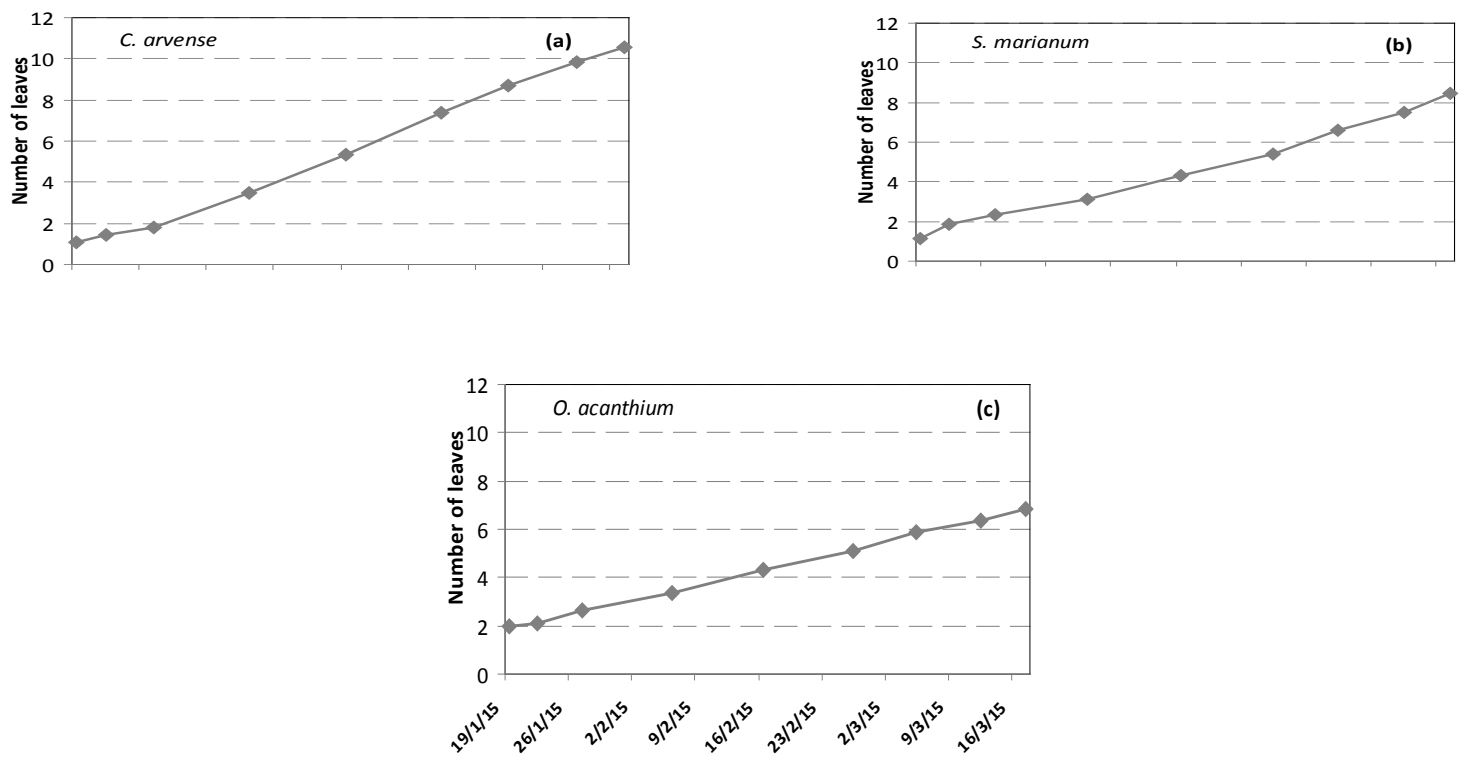

Fig.1. Number of leaves of a) C. arvense, b) S. marianum and c) $O$. acanthium plants

\section{RESULTS AND DISCUSSION}

Data analysis confirmed that seed germination and seedling emergence were high for all species and biotypes. More specifically, both biotypes of $C$. arvense and two out of three biotypes of $O$. acanthium had seed germinability higher than 90\%. Seedling emergence was also satisfactory with new seedlings offering chances for identification between the three species.

Regarding growth rate and earliness, there were significant differences between the several species. In particular, S. marianum had the highest growth rate and the earliest flowering (Karkanis et al., 2011). On the contrary, growth rate of one $O$. acanthium was very low, while $C$. arvense had intermediate values (with a biotype with a very high growth rate as shown in Fig.1) and a better response to drought stress among all the three thistles. It has to be noted that biotypes originated from arable fields had higher biomass production, probably because of their higher competitiveness (Karkanis et al., 2011).

\section{CONCLUSIONS}

In the present study, it was demonstrated that there is a potential of exploitation of thistles according to their many uses. Seed germination, seedling emergence, first growth, biomass production and earliness of some biotypes seem rather satisfactory, while the high genetic variability of these three weeds can be used as a source for any future breeding attempts.

\section{REFERENCES}

1. Karkanis A., Bilalis D, Efthimiadou A (2011). Cultivation of milk thistle (Silybum marianum L. Gaertn.), a medicinal weed. Industrial Crops \& Products 34:825-830.

2. Khan ZUH, Ali F, Khan SU, Ali I (2011). Phytochemical study on the constituents from Cirsium arvense.Mediterranean Journal of Chemistry 1(2):64-69.

3. Lajter I, Csupor-Löffler B, Orbán-Gyapai O, Jedliszki N, Forgo P, Vasas A, Hohmann J (2013). Bioactivity-guided isolation of compounds with xanthine oxidase inhibitory activity from Onopordum acanthium. Zeitschrift für Phytotherapie 34 (S 01):V24.

4. Miller S, Fornstrom K, Mesbah A (1994). Canada thistle control and competition in sugarbeets. Journal of Sugar Beet Research 31:87-96. 